\title{
Spatial autocorrelation of tree attributes in naturally regenerated managed beech (Fagus sylvatica) forests in the Beskid Niski Mountains, southern Poland
}

Received: 02 May; Accepted 03 September 2013

\begin{abstract}
European beech (Fagus sylvatica L.) is a widely distributed forest tree species in central, southern and western Europe. In Poland it reaches the eastern limit of its natural range. The three forest stands selected for the analysis presented here are located in the Dukla Forest Inspectorate, southern Poland in the Beskid Niski Mountains. The measurement plots were rectangular, 0.35 ha each, established under homogenous conditions. The origin of all stands is natural and up to now they were thinned several times according to selective thinning method. The main tree species on each plot is European beech. In each stand $(x, y)$ coordinates, the species, total heights of trees and their diameters at breast height were recorded. Total tree height, diameter, basal area and tree volume were considered as marks in statistical analysis. The aim of this paper is to find out the differences in the spatial autocorrelation of different tree marks as well as to explain the reasons for differences if they were observed. The empirical mark correlation functions indicated that there is a negative spatial correlation of all these marks in all three forest stands, i.e. trees close together tend to have smaller marks than the average in the stand. No significant spatial correlation was found for the tree heights. Diameter, basal area and volume show some correlation, but only in one stand a deviation test showed that the detected spatial correlation is significant. The mark variograms indicated that neighboring trees tended to have similar sizes.
\end{abstract}

Additional key words: spatial structure, spatial correlation function, mark variogram, Fagus sylvatica

Addresses: J. Szmyt, Departament of Silviculture, Faculty of Forestry, Poznan University of Life Sciences (corresponding author), ul. Wojska Polskiego 69,60-625 Poznań, Poland; e-mail: jszmyt@up.poznan.pl; D. Stoyan, Instiut of Stochastics, TU Bergakademie Freiberg, 09596 Freiberg, Germany

\section{Introduction}

Forests are very complex natural systems, where different organisms find the suitable habitat for their living. Forest complexity results from heterogene- ity of the structure created by different ecological processes operating at different spatial scales and time (Pommerening 2002; Fortin and Dale 2005). It is assumed that the more structured is a forest (higher heterogeneity), the more biodiversity can 
be observed and the more stable it is (Pommerening 2002). Forest scientists as well as forest practitioners are interested in recognition and understanding the spatial structure - in terms of horizontal and vertical aspects - because of two reasons: ecological and economical. From the ecological point of view knowledge on the spatial structure leads to better insight in the natural processes running in the forest and thus to better understanding of the natural forces creating the current structure of the population. Economical reasons result from the necessity of the use of ecological information in modern management of forest resources, which implies that a certain structure of a stand often requires adapted silvicultural treatment (Pommerening 2002; Lexerød and Eid 2006; Pretzsch 2010). On the other hand each silvicultural treatment, e.g. thinning, influences the spatial structure of the forest and it should be taken into consideration during their planning.

Obviously, trees in the forests are not independent but they influence each other (Legendre and Fortin 1989; Penttinen et al. 1992; Gavrikov and Stoyan 1995; Wälder and Wälder 2008; Law et al. 2009). Moreover, the relative locations of trees in space with respect to their neighbors is almost always related to their sizes (Picard et al. 2009). Foresters sometimes can make use of knowledge on interactions between trees, especially in case of mixed forests, when planning silvicultural operations.

Recently, interaction between trees and tree attributes have been analyzed using marked point process statistics. In the theory of point processes a mark is a value assigned to a point; in the forestry context the "points" are the tree locations and the "marks" are tree attributes such as species, diameter or height. The latter two marks are examples of "quantitative" marks, while the first is a "qualitative" mark; the present paper considers only quantitative marks.

Applications of marked point process statistics in forest sciences can be found in Penttinen et al. (1992), Wälder and Stoyan (1996), Degenhardt (1999), Stoyan and Penttinen (2000), Gavrikov and Stoyan (1995), Pommerening (2002), Kint et al. (2003), Wälder and Wälder (2008), Suzuki et al. (2008), Law et al. (2009), Grabarnik et al. (2011), Ledo et al. (2011), Pommerening and Särkkä (2013).

Mark correlation function or mark variograms describe a multitude of scales of inter-tree distances (Penttinen et al. 1992; Gavrikov and Stoyan 1995; Penttinen 2006; Pommerening 2002; Kint et al. 2003; Suzuki et al. 2008; Comas et al. 2011; Grabarnik et al. 2011; Ledo et al. 2011; Pommerening and Särkkä 2013). Studies on spatial correlations of quantitative marks can answer questions on differences between marks in dependence on the distances of the corresponding trees (Illian et al. 2008). The null hypothesis in correlation tests is realized by random labeling, where the points are fixed but the marks are randomly allocated (Illian et al. 2008).

This paper presents an application of mark correlation functions and mark variogram for the description of spatial correlations of various marks of trees in natural beech (Fagus sylvatica L.) forests in the Beskid Niski Mountains, southern Poland. The aim of this paper is to analyze differences in the spatial correlation of such marks as diameter at the breast height (further in text as DBH), total height, basal area and volume, and to find out differences in the type of spatial correlation as well as to explain reasons for that different behavior.

\section{Methods}

\section{Study sites and data collection}

Three experimental temporal plots are analyzed in the present paper, which are located in the Dukla Forest District (N 21.40, E 49.33), southern Poland in the Beskid Niski Mountains. The climatic conditions there are typical for the Carpathians: the average annual temperature is $+7.4^{\circ} \mathrm{C}$, with mean annual precipitation of $770 \mathrm{~mm}$. The vegetation period lasts 170-190 days. Leached brown soils and brown soils dominate (total ca. 84\%) on the plots.

The measurement plots were rectangular $(70 \mathrm{~m} \times$ $50 \mathrm{~m}$ ), each of size 0.35 ha. They were established under homogenous conditions in terms of forest site type. The latter can be described as upland fresh forest (Forest Management Plan for years 2008-2017).

The average age of the stands was similar, 77 (stands B and C) and 82 (stand A) years. The origin of all stands is natural and up to now they were thinned several times according to selective thinning method (no detailed information on the intensity of thinning treatments is known to the author).

The European beech (Fagus sylvatica L.) is the main tree species in each stand. Other tree species, like silver fir (Abies alba L.), pedunculate oak (Quercus robur L.), sycamore maple (Acer pseudoplatanus L.) appear in mixture and their share in the species composition is very small. No large gaps caused by natural disturbances were observed.

On each mesurement plot for each tree the planar coordinates $(x, y)$, the species and the diameters at the breast height and total heights were measured using the measurement tape and Vertex III altimeter. Coordinates of each tree were evaluated using teodolith and laser rangefinder Vertex III. Then for each tree volume and basal area were calculated. Tree volume was calculated - with the assumption that the trees are conical in shape - by

$$
v_{i}=b a_{i} \cdot h_{i} / 3
$$


while basal area $b a$ is determined by

$$
b a_{i}=0,00007854 \cdot d_{i}^{2}
$$

\section{Data analysis}

The aim of statistical analysis was to find out which spatial correlations exist between the trees in the three plots and how the different tree characteristics behave. Second-order characteristics of marked point processes are the right tool for describing the spatial correlation of different marks. Summary characteristics such as mark correlation function $k_{m m}(r)$ and mark variogram $\gamma_{m}(r)$ characterize not only the variability of the point dispersion but also the variability of marks associated with points (Illian et al. 2008).

The mark correlation function $k_{m m}(r)$ helps to detect correlations in the sense of mutual stimulation or inhibition of trees (Pommerening 2002; Illian et al. 2008). It expresses the normalized mean of the product of the marks of the points in a point pair of distance $r$ as function of distance $r$. If the marks are independent, then this function is equal to 1 for all $r$. A value of $k_{m m}(r)$ larger than 1 indicates that point pairs of the distance $r$ tend to have on average marks larger than the mean mark, i.e. there is mutual stimulation or positive correlation. If the function is for some $r$ smaller than 1 it means that points belonging to point pairs of inter-point distance $r$ have on average marks smaller than the mean mark, which indicates mutual inhibition or negative correlation (Penttinen et al. 1992; Penttinen 2006; Comas and Mateu 2007; Illian et al. 2008). For large distances $r$ the function $k_{m m}(r)$ converges to 1 , while empirical mark correlation functions fluctuate around 1 . The distance at which the function comes to the value 1 indicates the correlation range (Illian et al. 2008).

The mark variogram, $\gamma_{m}(r)$, characterizes another aspect of spatial correlation. By definition it is the half mean squared difference of the marks belonging to point pairs with distance $r$. Thus it is a measure of spatial mark similarity in dependence on distance. Small values of $\gamma_{m}(r)$ indicate that the marks of the points in pairs of distance $r$ tend to be similar (they can be simultaneously large or small), while large values indicate that they are different (Wälder and Stoyan 1996; Illian et al. 2008).

However, before a spatial correlation analysis can start, it must be checked whether there is really a significant spatial correlation in the given plot. In the present paper this is carried out by means of a deviation test, a simulation test as described in Grabarnik et al. (2011). The summary statistic used there are the $L-$ and $L_{m m}$-function (Penttinen 2006; Illian et al. 2008).
As recommended in Grabarnik et al. (2011), the null hypothesis of mark independence is tested via random relabeling (Illian et al. 2008; Grabarnik et al. 2011; Ledo et al. 2011). This means that the points of the given pattern are fixed while the marks are independently allocated by permutation to the points. The corresponding $L_{m m}(r)$ functions are compared with the empirical $L(r)$ function. More precisely, in the test a measure $u$ of deviation between the $L(r)$ function and the $L_{m m}(r)$ function is determined for the data and for the relabeled point patterns. The deviation measure $u_{i}$ is calculated as:

$$
u_{i}=\max _{r_{\min } \leq r \leq r_{\max }}\left|\hat{L}_{i, m}(r)-\hat{L}(r)\right|
$$

for the $i$-th simulated sample, with $i=1,2, \ldots, k$, where $r_{\min }$ and $r_{\max }$ are suitable distances. Below they are chosen as 0 and $10 \mathrm{~m}$, respectively. For all relabeled patterns the function $L(r)$ is the same.

These $u_{i}$ and an analogous $u, u_{\text {emp }}$, for the empirical $L_{m m}(r)$ are arranged in increasing order. If $u_{e m p}$ has a high position among these values then the independence hypothesis is rejected. After calculating the deviation measures of $u_{i}$, the $p$ value of test can be calculated according to the formula (Illian et al. 2008; Grabarnik et al. 2011):

$$
p=\frac{s+1}{k+1}
$$

where $s$ is the number of cases where $u_{i}$ is larger than $u_{e m p}$ and $k$ is a number of simulations.

To understand the reasons for possible rejection of the null hypothesis of independence, envelopes on the base of 99 simulations (using relabeling) are determined for $k_{m m}(r)$ and $\gamma_{m}(r)$. However, these envelopes are used only as a tool for data analysis and do not serve for formal testing.

All computations were conducted in $R$ environment (R Core Team 2002) using "Spatstat" and "Marktests" packages (Baddeley and Turner 2005; Myllamäki and Grabarnik 2011).

\section{Results}

Some general statistics for the stands are presented in Table 1. The values of coefficient of variation show that the variability of volume and basal area was the highest. The smallest variability was observed for tree heights (Table 1). Diameter and height distributions are presented on Fig. 1. According to height distributions all stands can be described as single layered. 
Table 1. Basic statistical characteristics of analyzed Fagus sylvatica forests

\begin{tabular}{|c|c|c|c|c|c|c|c|c|c|c|c|c|}
\hline & \multicolumn{3}{|c|}{ DBH $(\mathrm{cm})$} & \multicolumn{3}{|c|}{ height (m) } & \multicolumn{3}{|c|}{ basal area $\left(\mathrm{m}^{2}\right)$} & \multicolumn{3}{|c|}{ volume $\left(\mathrm{m}^{3}\right)$} \\
\hline & Stand A & Stand B & Stand C & Stand A & Stand B & Stand C & Stand A & Stand B & Stand C & Stand A & Stand B & Stand C \\
\hline mean & 30,1 & 36,3 & 32,4 & 24,6 & 29,8 & 28,3 & 0,08 & 0,11 & 0,09 & 0,72 & 1,14 & 0,84 \\
\hline $\begin{array}{l}\min \\
\max \end{array}$ & $\begin{array}{r}8,5 \\
52,0\end{array}$ & $\begin{array}{l}10,5 \\
56,5\end{array}$ & $\begin{array}{l}10,0 \\
49,0\end{array}$ & $\begin{array}{r}9,3 \\
32,0\end{array}$ & $\begin{array}{l}23,5 \\
38,0\end{array}$ & $\begin{array}{l}14,3 \\
37,0\end{array}$ & $\begin{array}{l}0,01 \\
0,21\end{array}$ & $\begin{array}{l}0,01 \\
0,25\end{array}$ & $\begin{array}{l}0,01 \\
0,19\end{array}$ & $\begin{array}{l}0,02 \\
2,09\end{array}$ & $\begin{array}{l}0,08 \\
2,79\end{array}$ & $\begin{array}{l}0,07 \\
1,97\end{array}$ \\
\hline SD & 10,7 & 8,92 & 7,82 & 5,4 & 2,25 & 3,0 & 0,05 & 0,05 & 0,04 & 0,52 & 0,58 & 0,42 \\
\hline CV (\%) & 35,5 & 24,6 & 242 & 22,0 & 7,6 & 10,7 & 62,5 & 45,5 & 44,5 & 71,3 & 50,9 & 44,5 \\
\hline
\end{tabular}

$\mathrm{SD}$ - standard deviation, CV - coefficient of variation.

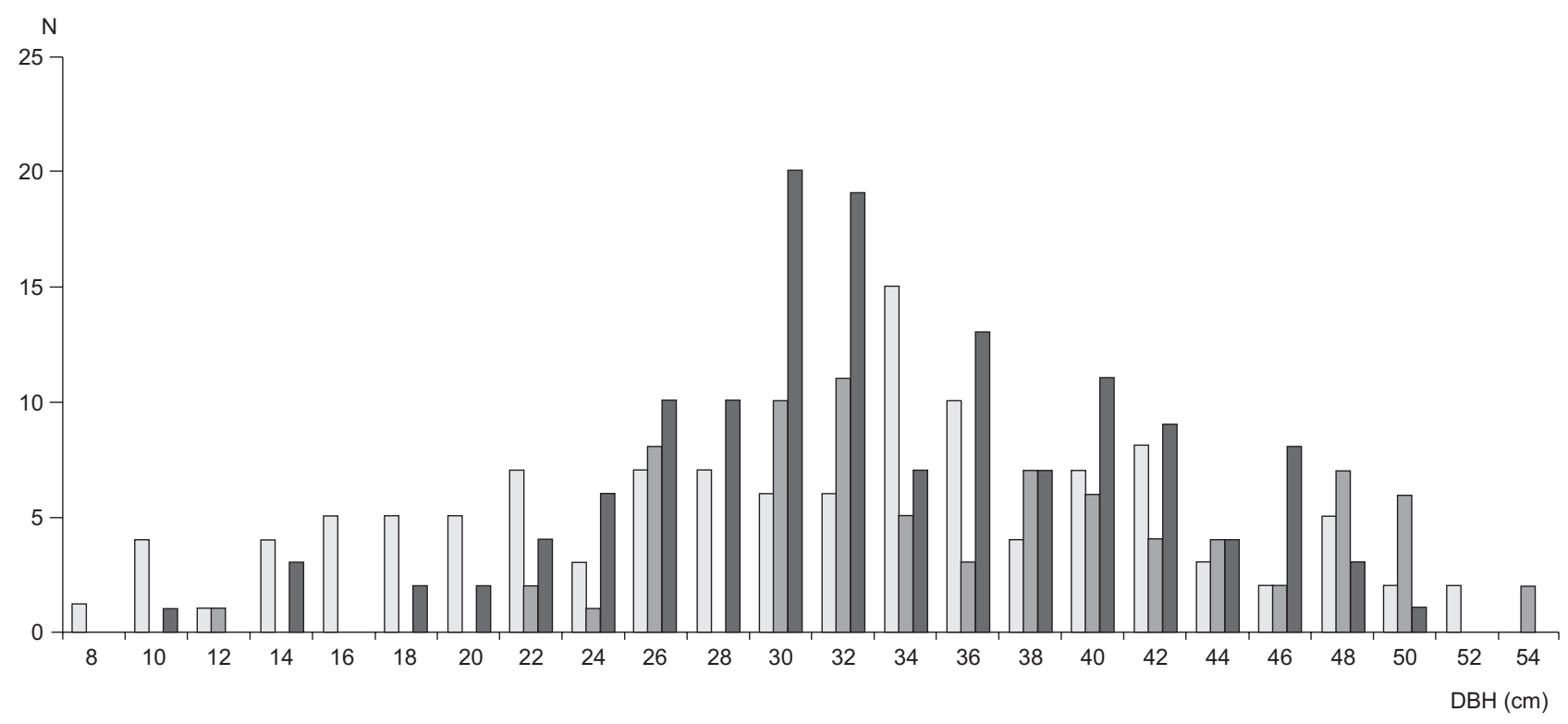

$\square \mathrm{A} \quad \square \mathrm{B} \quad \square \mathrm{C}$

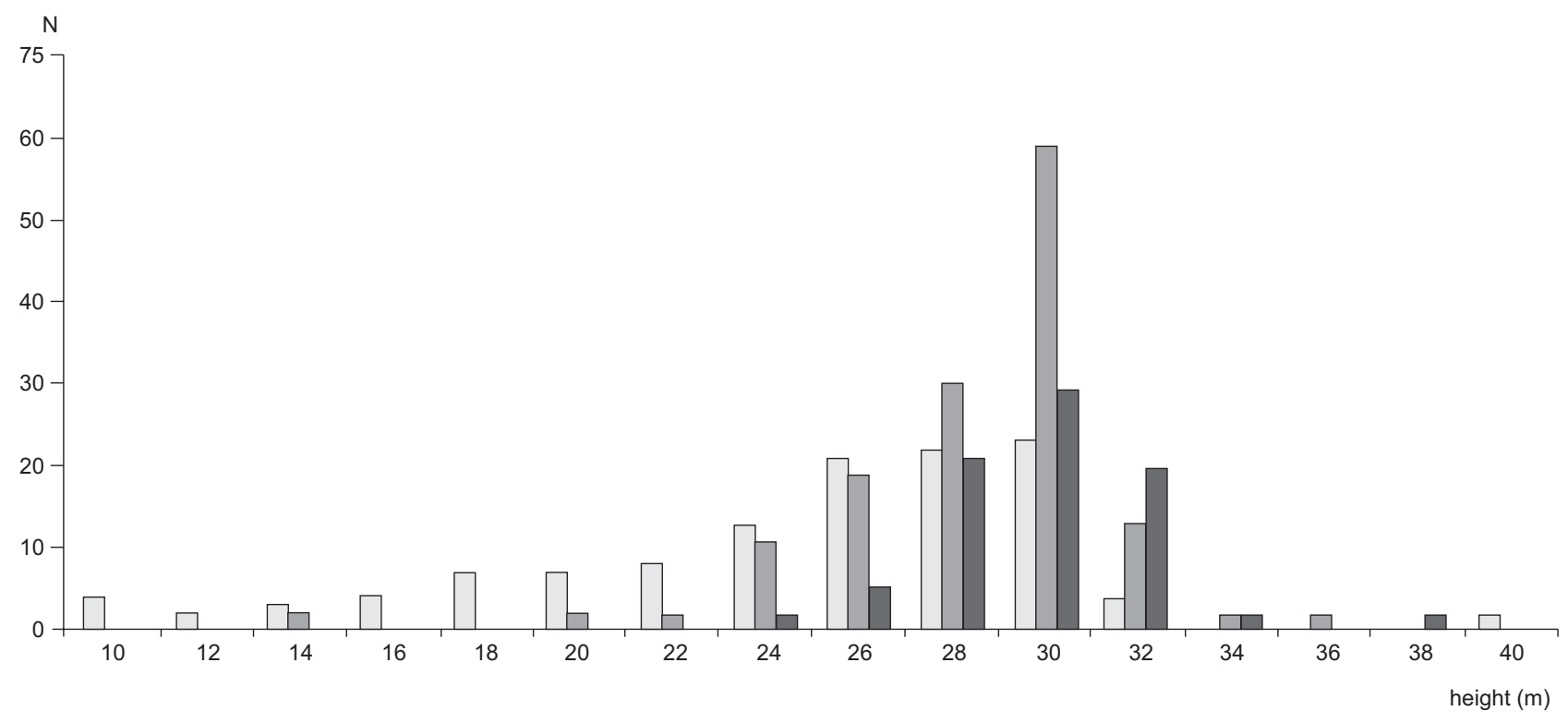

$\square$ A $\square$ B $\square \mathrm{C}$

Fig. 1. DBH and height distributions for the analyzed forest stands (A, B and C)

\section{Stand A}

Mark correlation function $\mathrm{k}_{\mathrm{mm}}(\mathrm{r})$

The values of the mark correlation function for all four variables are lower than 1 and the function is increasing continuously up to $2-3 \mathrm{~m}$. This negative correlation means that pairs of trees tend to have smaller marks than the average for the stand. Above the distance $2-3 \mathrm{~m}$ the function fluctuates irregularly. 


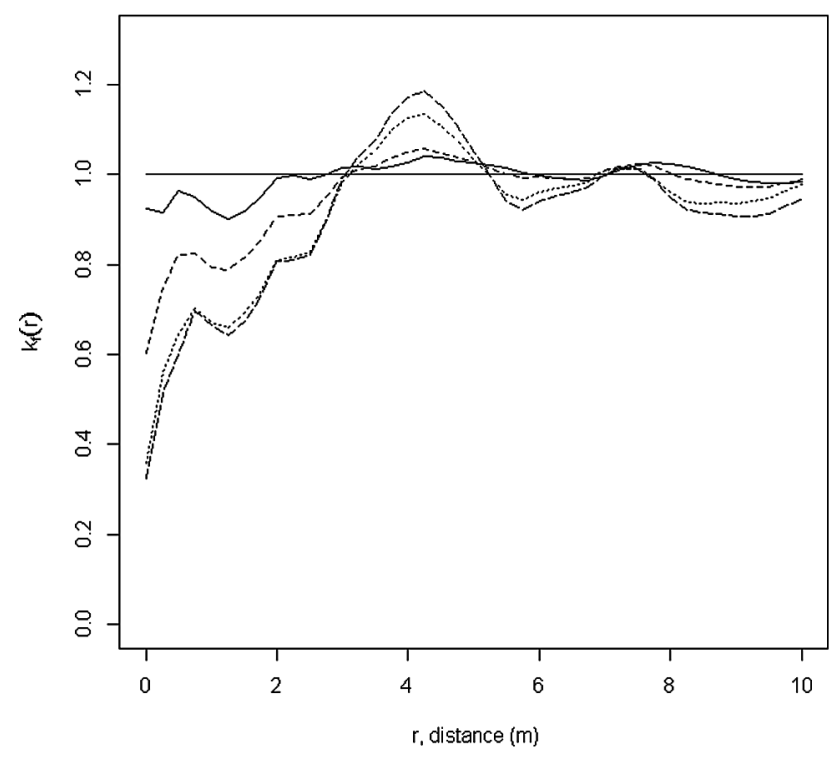

Fig. 2. Empirical mark correlation functions for four tree characteristics in stand A (height - solid line, DBH dashed line, basal area - dotted line, volume - longdashed line)

Fig. 2 shows that the spatial correlation for height is the weakest and the correlation range for this tree characteristic is the shortest (ca. $2 \mathrm{~m}$ ). DBH, volume and basal area are stronger correlated than height (since the values of $k_{m m}(r)$ are smaller) and the range of correlation for them is a bit larger. Note that the course for the mark correlation function for volume and basal area is almost identical.

\section{Mark variogram $\gamma_{\mathrm{m}}(\mathrm{r})$}

Fig. 3 shows empirical mark variograms for the four marks, normalized so that the asymptote is always 1 . All variograms look like "good" geostatisti-

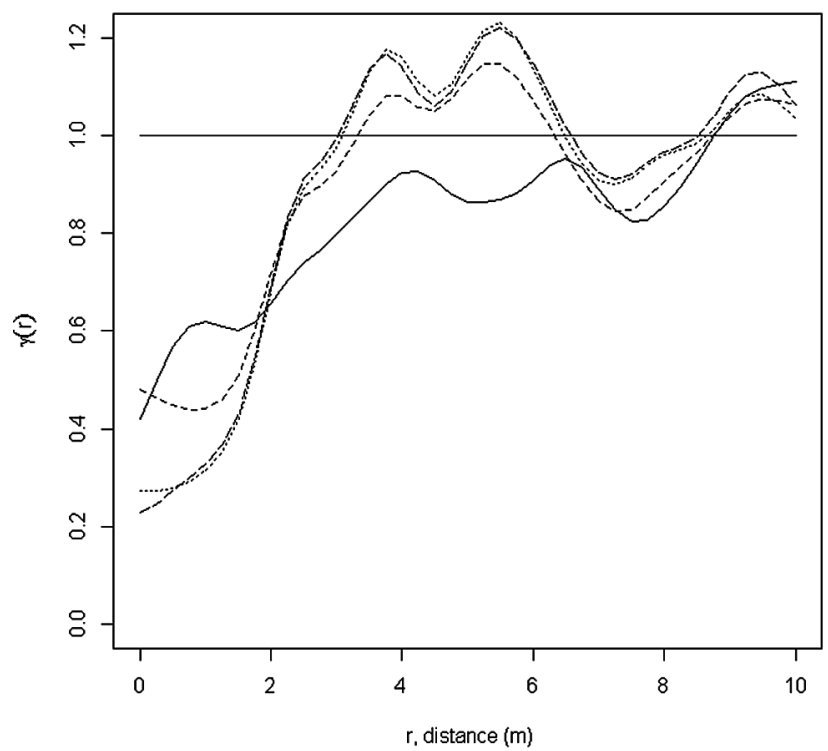

Fig. 3. Empirical mark variograms for different tree characteristics in stand A (explanations - see Fig. 2)
Table 2. $p$-values of deviation test for different marks in analyzed beech stands

\begin{tabular}{lccc}
\hline & Stand A & Stand B & Stand C \\
\hline height & 0,63 & 0,41 & 0,36 \\
DBH & 0,10 & 0,01 & 0,10 \\
basal area & 0,17 & 0,01 & 0,26 \\
volume & 0,21 & 0,01 & 0,37 \\
\hline
\end{tabular}

cal variograms (i.e. they are increasing for smaller distances) and show that indeed trees close together tend to have similar marks. The range of correlation obtained here is around $9 \mathrm{~m}$ for height and $3 \mathrm{~m}$ for the other three marks.

Though the observed correlations may be plausible, deviation tests (Table 2) for the marks showed that all observed spatial correlations are not significant. This means that the hypothesis of spatial independence of the tree marks should not be rejected.

\section{Stand B}

\section{Mark correlation function $\mathrm{k}_{\mathrm{mm}}(\mathrm{r})$}

Mark correlation functions indicated negative spatial correlation of marks. Similarly to the stand A, the weakest spatial correlation was observed for the heights, for which the function was fluctuating around the value 1 indicating spatial independence of this mark. However, for the other three attributes - DBH, basal area and volume - the function was clearly smaller than 1 (negative correlation) and the correlation range was longer than for stand $\mathrm{A}$, namely $6 \mathrm{~m}$ (Fig. 4).

\section{Mark variogram $\gamma_{\mathrm{m}}(\mathrm{r})$}

The mark variograms (Fig. 5) have an interesting form, as also observed elsewhere Wälder and Stoyan

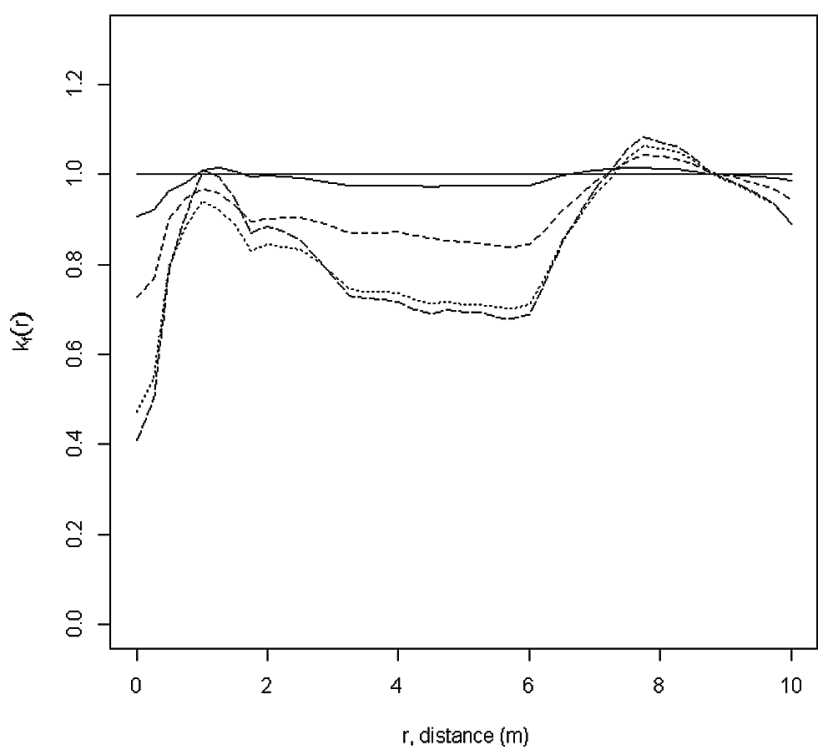

Fig. 4. Empirical mark correlation functions for four tree characteristics in stand B (explanations - see Fig. 2) 


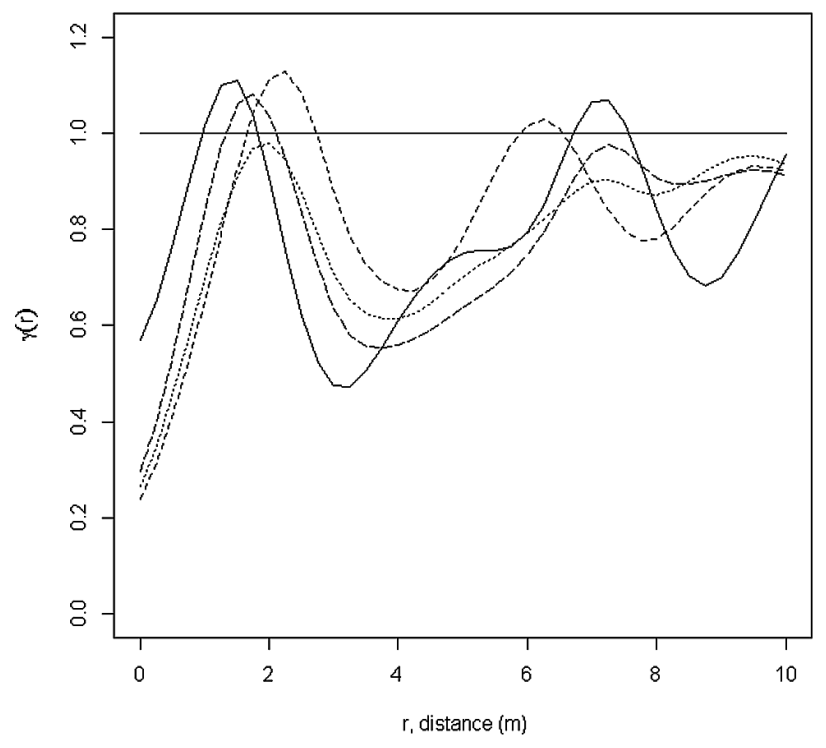

Fig. 5. Empirical mark variograms for different tree characteristics in stand B (explanations - see Fig. 2)

(1996). Data analysis showed that there is one pair of trees of distance $2 \mathrm{~m}$ with a big difference of marks which causes the maximum of $\gamma_{m}(r)$ at $r=2 \mathrm{~m}$. If this pair would be eliminated, a normal geostatistical form of the mark variogram (increase of $\gamma_{m}(r)$ with increasing $r$ ) is obtained.

Deviation tests for the marks showed that for all marks - except tree height - the detected spatial correlation is significant.

\section{Stand C}

For stand $\mathrm{C}$ the spatial correlations are similar as for stand A, see Fig. 6 and 7. The mark variogram does not show any spatial correlation, as is also shown by the deviation test of the independence hypothesis.

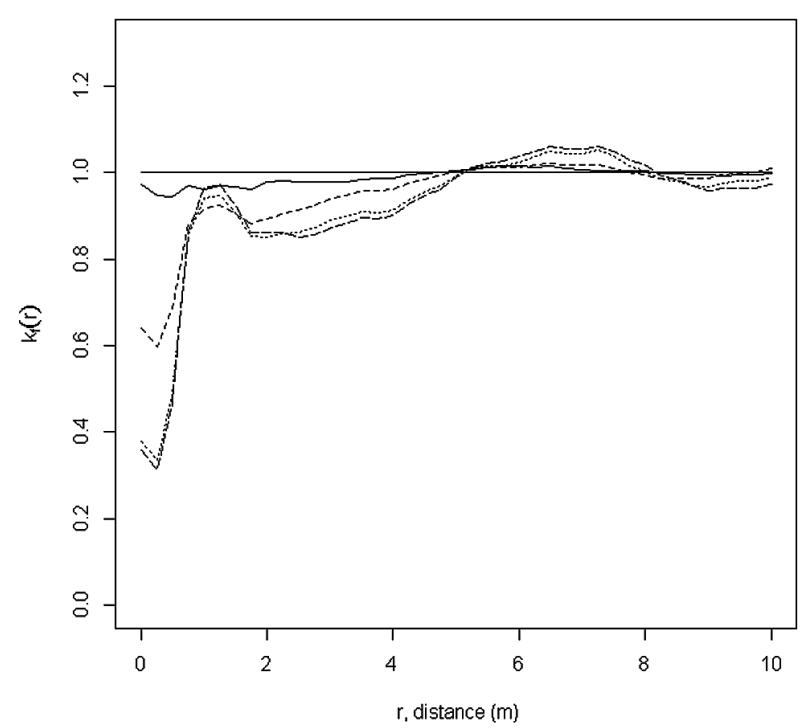

Fig. 6. Empirical mark correlation functions for four tree characteristics in stand C (explanations - see Fig. 2)

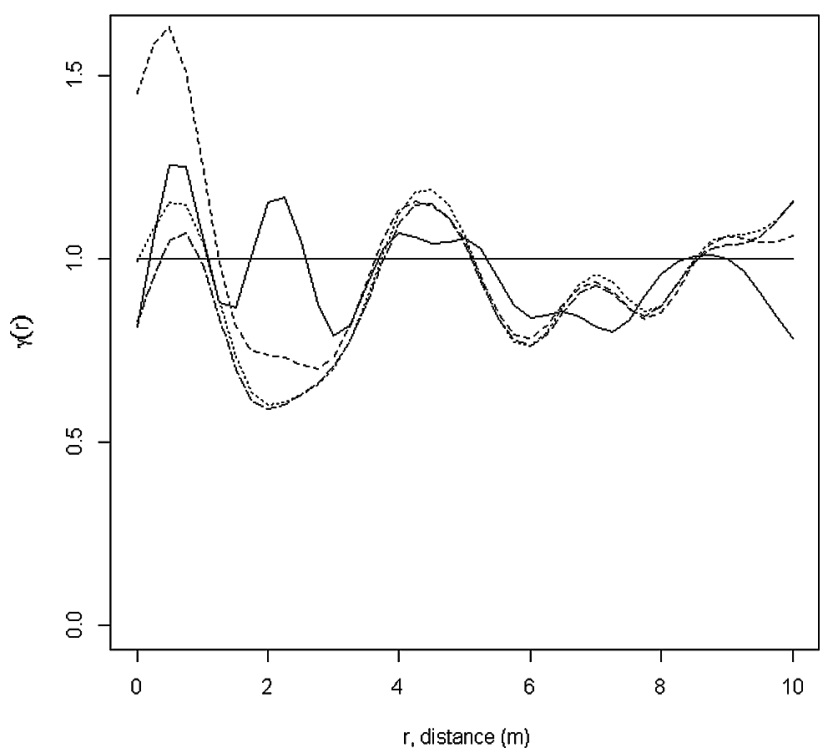

Fig. 7. Empirical mark variograms for different tree characteristics in stand C (explanations - see Fig. 2)

\section{Discussion and conclusions}

Our results indicated that tree heights in the analyzed beech stands were not correlated spatially. The absence of spatial correlation of heights was also stated by Penttinen et al. (1992) for pines and birches. A simple explanation of this observation is the applied treatment and, furthermore, the competition between trees. Obviously, in the forest investigated, the low thinning method was applied (suppressed and dead trees are removed from the stand), which leads to some homogenization of the vertical structure of the forest. In terms of correlation the effect of thinning may be expressed as follows: originally in an even-aged forest there is negative correlation. Low thinning tends to strengthen positive correlation, and both forms of correlation may cancel out to obtain no correlation. In other ecological situations also positive correlation of tree heights is possible, for example in forests with trees of different age, where young trees appear in clusters. An interesting example is discussed in Suzuki et al. (2008). In an even-aged Abies forests in Japan they observed that the correlation of tree heights changed from positive to "no correlation" during the early stage of stand development, whereas in the older stages of forest development it was changed again from "no correlation" to negative one. Positive spatial correlation for tree heights was observed by Kint et al. (2003) in planted Scots pine stands being converted into mixed broadleaved forest.

Wälder and Wälder (2008) gave an example of negative spatial correlation of tree heights of spruces 
in a beech-spruce forest. For beeches alone they observed a positive correlation.

Our results showed that $\mathrm{DBH}$, basal area and volume behaved differently in comparison to tree heights: negative correlation was always observed, but it was stronger than for the heights. So, they support the earlier observations. Penttinen et al. (1992) noted the lack of spatial correlation of DBH in a thinned spruce stand and negative correlation for birches in a birch-pine stands. Negative correlation of DBH was observed in a sweet chestnut coppice stand in France (Goulard et al. 1995) and in a 150-year old beech forest with natural regeneration and moderately thinned from above (Degenhardt 1999). However, in planted ash-lime forest, where thinning operations were carried out in favor of lime trees, DBH (for lime only) was not spatially correlated (Degenhardt 1999). Negative correlation of DBH was also observed by Pommerening (2002) for young planted Douglas firs as well as for 53-year old beeches. Only little spatial correlation of DBH was stated by Mason et al. (2007) in a young pine plantation, whereas in case of natural old pine forests they observed negative correlation of $\mathrm{DBH}$.

Spatial correlation of volume and was not so often analyzed than that of DBH. We refer to Mateu (2000), who found positive correlation for Ulex parviflorus and negative one for Thymus vulgaris.

In general the empirical mark variograms suggest that trees close together tend to have similar marks, which we explain as a result of thinning treatment carried out in these stands.

Our results, based on a local case study for beech forests, lead to the following conclusions:

1. The observed mature and managed beech forests show only weak spatial correlation of tree attributes like height, DBH, volume and basal area.

2. Different tree parameters - e.g. DBH and height can have different forms of spatial correlation.

3. Tree heights showed lack of spatial correlation or weaker correlation than other tree attributes.

\section{Reference}

Baddeley A., Turner R. 2005. Spatstat: an R package for analyzing spatial point patterns. Journal of Statistical Software 12: 1-42.

Comas C., Delicado P., Mateu J. 2011. A second order approach to analyze spatial point patterns with functional marks. Test 20: 503-523.

Comas C., Mateu J. 2007. Modeling forest dynamics: a perspective from point process methods. Biometrical Jorurnal 49: 176-196.

Degenhardt A. 1999. Description of tree distribution patterns and their development through marked Gibbs processes. Biometrical Journal 41: 457-470.
Fortin M.-J., Dale M. 2005. Spatial analysis: a guide for ecologists. Cambridge University Press, Cambridge, UK. 365 pp.

Gavrikov V.L., Stoyan D 1995. The use of marked point processes in ecological and environmental forest studies. Environmental and Ecological Statistics 2: 331-344.

Goulard M., Pagès L., Cabanettes A. 1995. Marked point process: using correlation functions to explore a spatial data set. Biometrical Journal 37: 837-853.

Grabarnik P., Myllymäki M., Stoyan D. 2011. Correct testing of mark independence for marked point patterns. Ecological Modelling 222: 3888-3894.

Illian J., Penttinen A., Stoyan H., Stoyan H. 2008. Statistical analysis and modeling of spatial point patterns. John Wiley \& Sons Ltd. Chichester, pp. 341-361.

Kint V., Van Meirvenne M., Nachtergale L., Geudens G., Lust N. 2003. Spatial methods for quantifying forest stand structure development: a comparison between nearest-neighbor indices and variogram analysis. Forest Science 49: 36-49.

Law R., Illian J., Burslem D.F.R.P., Gratzer G., Gunatilleke C.V.S., Gunatilleke I.A.U.N. 2009. Ecological information from spatial patterns of plants: insights from point process theory. Journal of Ecology 97: 616-628.

Legendre P., Fortin M.-J. 1989. Spatial pattern and ecological analysis. Vegetatio 80: 107-138.

Ledo A., Condés S., Montes F. 2011. Intertype mark correlation function: A new tool for the analysis of species interactions. Ecological Modelling 222: 580-587.

Lexerød N.L., Eid T. 2006. An evaluation of different diameter diversity indices based on criteria related to forest management planning. Forest Ecology and Management 222: 17-28.

Mateu J. 2000. Second-order characteristics of spatial marked processes with applications. Nonlinear analysis: Real World Applications 1: 145-162.

Mason W.L., Connolly T., Pommerening A., Edwards C. 2007. Spatial structure of semi-natural and plantation stands of Scots pine (Pinus sylvestris L.) in northern Scotland. Forestry 80: 567-586.

Myllamäki M., Grabarnik P. 2011. Marktest. R Documentation.

Penttinen A., Stoyan D., Henttonen H. 1992. Marked point processes in forest statistics. Forest Science 38: 806-824.

Penttinen A. 2006. Statistics for marked point patterns. In: Yearbook of the Finnish Statistical Society 2006: 70-91.

Picard N., Bar-Hen A., Mortier F., Chadoeuf J. 2009. Understanding the dynamics of an undisturbed tropical rain forest from the spatial pattern of trees. Journal of Ecology 97: 97-108. 
Pommerening A. 2002. Approaches to quantifying forest structures. Forestry 75: 305-324.

Pommerening A., Särkkä A. 2013. What mark variograms tell about spatial plant interactions. Ecological Modeling 251: 64-72.

Pretzsch H. 2010. Forest dynamics, growth and yield. Springer-Verlag Berlin Heidelberg, pp. 223-285.

$\mathrm{R}$ Core Team 2002. R: A language and environment for statistical computing. R Foundation for Statistical Computing, Vienna, Austria. ISBN 3-900007-0, URL http://www.R-project.org/.

Stoyan D., Penttinen A. 2000. Recent application of point process methods in forestry statistics. Statistical Science 15: 61-78.
Suzuki S.N., Kachi N., Suzuki J.I. 2008. Development of a local size hierarchy causes regular spacing of trees in an even-aged Abies forest. Analysis using spatial autocorrelation and the mark correlation function. Annals of Botany 102: 435-441.

Wälder O., Stoyan D. 1996. On variograms in point process statistics. Biometrical Journal 38: 895905.

Wälder O., Wälder O. 2008. Analysing interaction effects using the mark correlation function. iForest 1: 34-38. 